\title{
Dynamic Absorption Model for Off-Gas Separation
}

\author{
Veronica J. Rutledge
}

July 2011

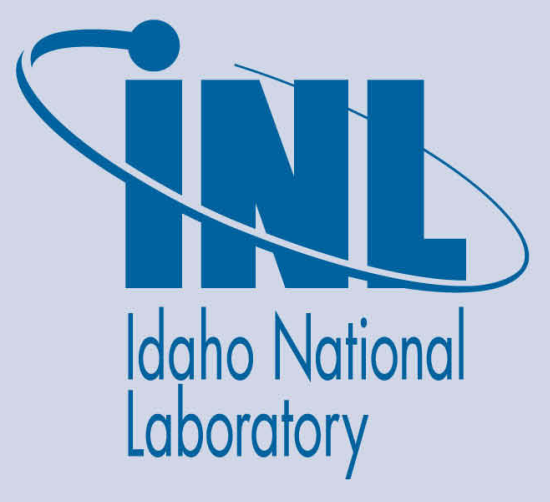

The INL is a U.S. Department of Energy National Laboratory operated by Battelle Energy Alliance 
INL/EXT-11-22796

FCRD-MDSM-2011-000227

\title{
Dynamic Absorption Model for Off-Gas Separation
}

\author{
Veronica J. Rutledge
}

July 2011

\author{
Idaho National Laboratory \\ Fuel Cycle Research \& Development \\ Separations and Waste Forms \\ Idaho Falls, Idaho 83415 \\ http://www.inl.qov
}

Prepared for the

U.S. Department of Energy Office of Nuclear Energy

Under DOE Idaho Operations Office

Contract DE-AC07-05ID14517 


\section{DISCLAIMER}

This information was prepared as an account of work sponsored by an agency of the U.S. Government. Neither the U.S. Government nor any agency thereof, nor any of their employees, makes any warranty, expressed or implied, or assumes any legal liability or responsibility for the accuracy, completeness, or usefulness, of any information, apparatus, product, or process disclosed, or represents that its use would not infringe privately owned rights. References herein to any specific commercial product, process, or service by trade name, trade mark, manufacturer, or otherwise, does not necessarily constitute or imply its endorsement, recommendation, or favoring by the U.S. Government or any agency thereof. The views and opinions of authors expressed herein do not necessarily state or reflect those of the U.S. Government or any agency thereof. 


\section{SUMMARY}

Modeling and simulations will aid in the future design of U.S. advanced reprocessing plants for the recovery and recycle of actinides in used nuclear fuel. The specific fuel cycle separation process discussed in this report is the off-gas treatment system. The off-gas separation consists of a series of scrubbers and adsorption beds to capture constituents of interest. Dynamic models are being developed to simulate each unit operation either as a stand-alone model or in series with multiple others.

The model described herein is a thermodynamic equilibrium and kinetics model for countercurrent, multistage absorption of gaseous species from a gas stream into a liquid stream. The generic equilibrium model can be used for different gas species as long as the key constants and assumptions are changed. The kinetic model, however, is unique to the gas species, and is currently based on $\mathrm{NO}$ and $\mathrm{NO}_{2}$. $\mathrm{The}$ model for $\mathrm{NO}_{\mathrm{x}}$ absorption is designed to enable modeling the performance of a counter-current $\mathrm{NO}_{\mathrm{x}}$ absorber used to capture $\mathrm{NO}_{\mathrm{x}}$ in a used fuel dissolver off-gas stream, for recycle back to the dissolver.

Inputs include liquid and gas stream constituents, column properties, liquid and gas phase reactions, number of stages, and inlet conditions. It simulates absorption by mass transfer and chemical reaction. The assumption of each stage being a discrete well-mixed entity was made. Therefore, the model is solved stagewise. The simulation output includes component concentrations in both phases as a function of time from which the rate of absorption is determined. Temperature of both phases is output as a function of time as well.

The model will be able to be used as a standalone model or in series with other off-gas separation unit operations. The current model is being generated based on $\mathrm{NO}_{\mathrm{x}}$ absorption; however, a future goal is to develop a $\mathrm{CO}_{2}$ specific model. The model will have the capability to be modified for additional absorption systems. The off-gas models, both adsorption and absorption, will be made available via the server or web for evaluation by customers. 


\section{TABLE OF CONTENTS}

SUMMARY iii

ACRONYMS $\mathrm{V}$

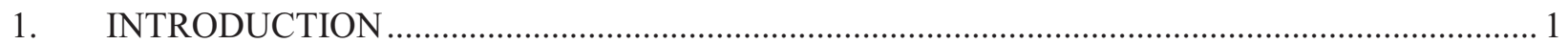

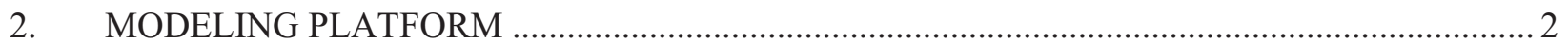

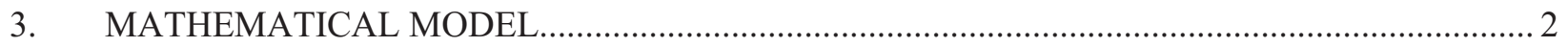

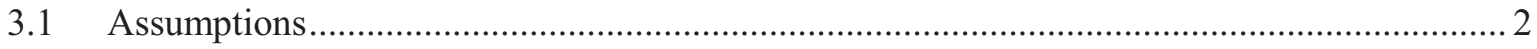

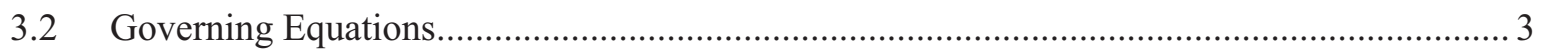

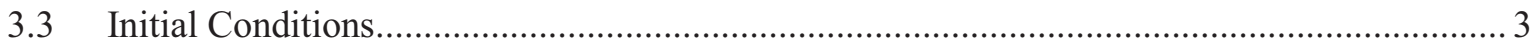

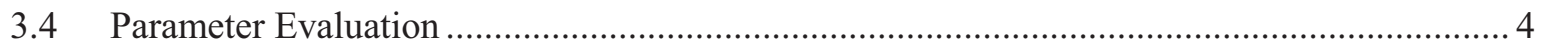

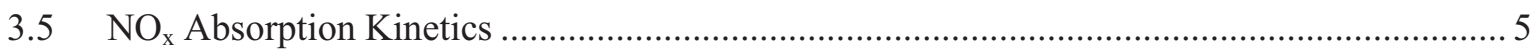

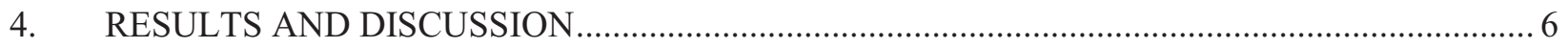

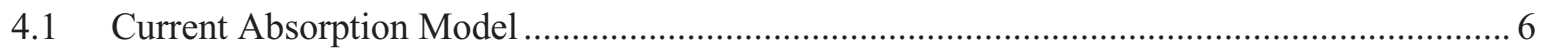

4.2 Future Absorption Model Work ...................................................................................... 7

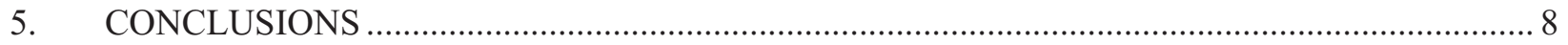

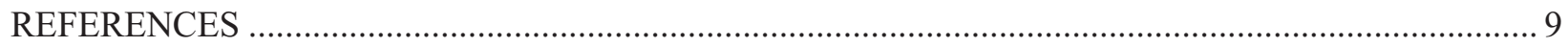

FIGURES

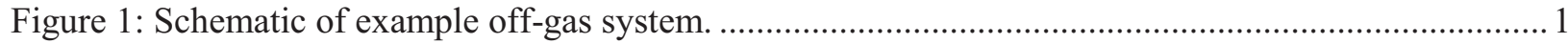

Figure 2: Discrete, stagewise model with countercurrent flow............................................................. 2

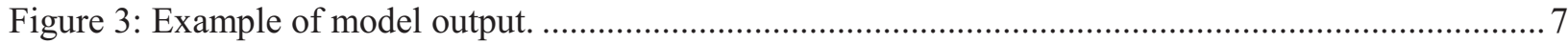

\section{TABLES}

Table 1: Reaction Properties for $\mathrm{NO}_{\mathrm{x}}$ Absorption .6 


\section{ACRONYMS}

C-14 Carbon-14

$\mathrm{CO}_{2} \quad$ Carbon Dioxide

CV Control Volume

FY Fiscal Year

gPROMS general Process Modeling System

$\mathrm{H}_{2} \mathrm{O} \quad$ Water

$\mathrm{HNO}_{2} \quad$ Nitrous Acid

$\mathrm{HNO}_{3} \quad$ Nitric Acid

I Iodine

IPSC Integrated Performance and Safety Codes

$\mathrm{Kr} \quad$ Krypton

$\mathrm{N}_{2} \mathrm{O}_{3} \quad$ Dinitrogen Trioxide

$\mathrm{N}_{2} \mathrm{O}_{4} \quad$ Dinitrogen Tetroxide

NEAMS Nuclear Energy Advanced Modeling and Simulation

NO Nitrogen Monoxide

$\mathrm{NO}_{2} \quad$ Nitrogen Dioxide

$\mathrm{NO}_{\mathrm{x}} \quad$ Nitrous Oxides

$\mathrm{O}_{2} \quad$ Oxygen

PSE Process Systems Enterprise

Xe Xenon 
Dynamic Absorption Model for Off-Gas Separation 


\section{SEPARATIONS AND WASTE FORMS DYNAMIC ABSORPTION MODEL FOR OFF-GAS SEPARATION}

\section{INTRODUCTION}

A capability of accurately simulating the dynamic behavior of advanced nuclear fuel cycle separation processes will provide substantial cost savings and many technical benefits in the future design of U.S. advanced reprocessing plants. The Nuclear Energy Advanced Modeling and Simulation (NEAMS) Program Safeguards and Separations (SafeSep) Integrated Performance and Safety Codes (IPSC) element is developing a dynamic plant level model which will allow simulations of separation processes for various configurations and operating conditions. This plant model will include the front end of the separations process (dissolution and potential voloxidation of the fuel), the separation processes, and the off-gas treatment system.

The reference case of unit operations for separation of off-gas consists of an interconnected series of adsorbers for the capture of tritium, $\mathrm{Kr}, \mathrm{Xe}$, and I, and scrubbers (absorbers) for the capture of $\mathrm{C}-14$ and $\mathrm{NO}_{\mathrm{x}}$ as shown in Figure 1. Detailed off-gas modeling requirements, developed in FY 2010, include the model being dynamic, allowing for various unit operations to be incorporated for comparison and being flexible to allow for variation in unit operation sequencing and the components modeled. ${ }^{1}$ An adsorption model was developed and documented in FY 2011 and is currently being validated with experimental data. $^{2}$ The unit operation within the off-gas treatment system described in this report is absorption.

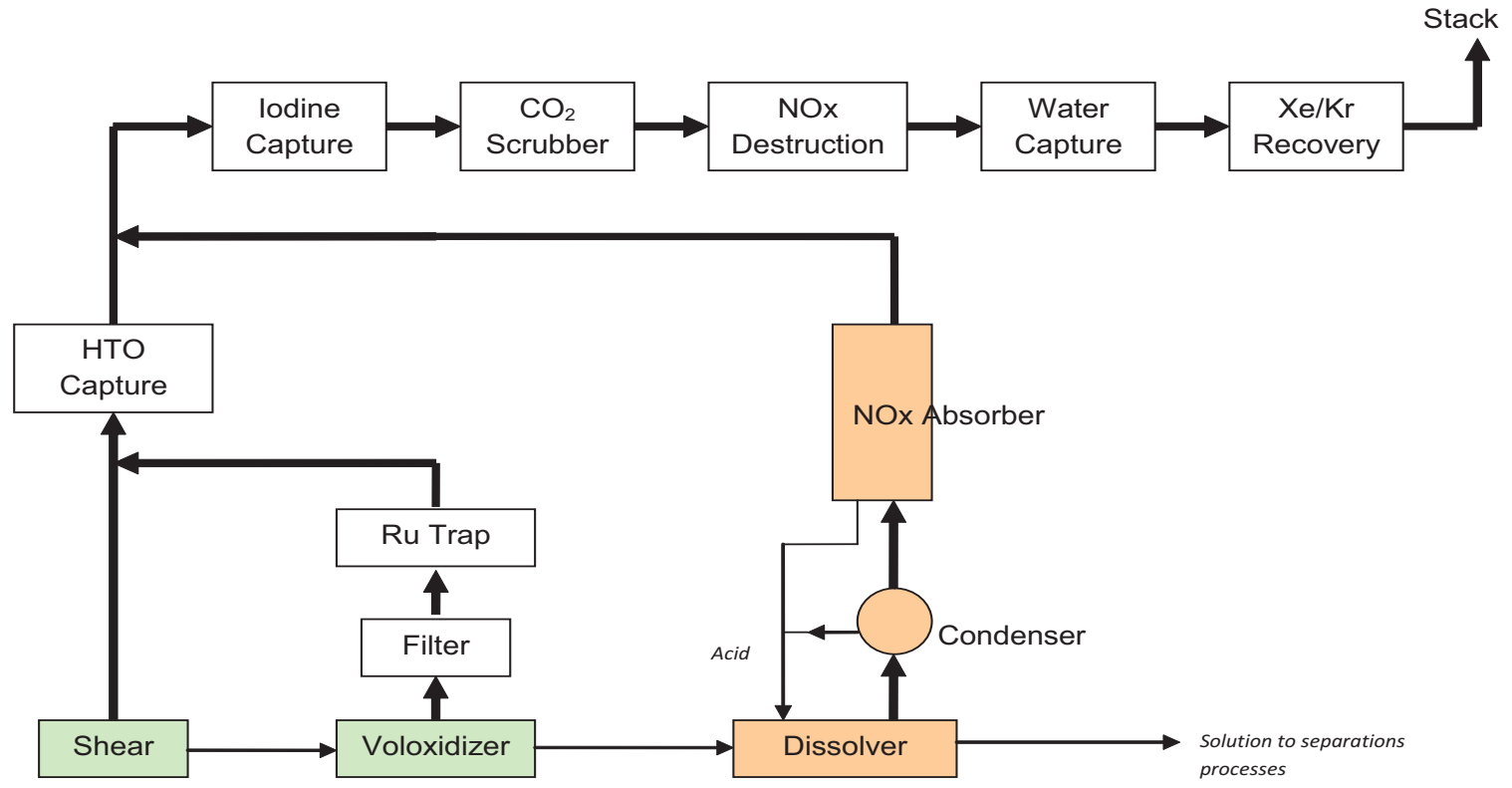

Figure 1: Schematic of example off-gas system.

Reactive processes comprised of both mass transfer and chemical reactions are very complex systems. Rigorous modeling of these processes often leads to very extended systems of equations which cannot be solved quickly enough. However, the model accuracy increases with rising complexity. Therefore, a model must be developed that achieves a sufficient accuracy at a feasible computation time. This paper focuses on the development of a dynamic, more generic model that will quickly and accurately simulate absorption processes. ${ }^{3}$ 
The objective of the modeling work presented herein was to solve the fundamental transport equations for an absorber in order to obtain a predictive unit operations model for separation of off-gas constituents. The model discussed in this report focuses on the absorption of $\mathrm{NO}_{\mathrm{x}}$ in a tray column absorber.

\section{MODELING PLATFORM}

The off-gas models are being developed using general Process Modeling System (gPROMS) software. The gPROMS platform is an advanced process modeling environment available from Process System Enterprise (PSE). The gPROMS package comes with a library of models standard to the chemical process and modeling disciplines. In addition to the library models, custom models can be developed via gPROMS code. It is this capability for which the architecture was really developed. Models can be easily connected by unit and stream terms or by the topology interface (drag-and-drop method) to develop flow sheets. The gPROMS platform is typically used for simulation, optimization, and parameter estimation.

The gPROMS package uses an equation oriented architecture supported by a suite of numerical solvers, and, therefore, is a very robust solver in which a simulation runs in a matter of seconds. Numerical algorithms used by gPROMS include, but are not limited to, finite difference, finite element, and various Gaussian quadrature techniques. The discretization method, order, and granularity, either uniform or nonuniform, of approximation can be specified by the modeler. The gPROMS package has a simple, user friendly programming language, efficient code diagnostics, efficiently manages discontinuities, and provides excellent customer support. This software interfaces with various other software packages through utilization of foreign objects. Examples of packages that gPROMS can be interfaced with are MS Excel, Matlab and Simulink, Fluent, and Aspen Plus. ${ }^{4}$

\section{MATHEMATICAL MODEL}

The absorption system being modeled is a discrete (tray column) system, is ratebased, and is solved stagewise. Each stage is modeled as a well mixed element. The direction of mass transfer is from the gas phase into the liquid phase and flow is countercurrent. Figure 2 shows a schematic exemplifying the stagewise system with a control volume $(\mathrm{CV})$ showing the well mixed element that the mass and energy balances were written around. The mechanism of absorption is by both mass transfer and chemical reaction. Rate-based models directly consider actual rates of the absorption mechanisms ${ }^{5}$ and are more appropriate in modeling reactive absorption processes. $^{6}$

\subsection{Assumptions}

To develop generalized governing equations for the absorption tray column, the following assumptions for the off-gas separation process were made:

- Discrete system

- Well mixed system

- Ideal gas behavior

- Constant flow rates

- Phase equilibrium at interface between liquid and gas phases

- Phase equilibrium follows Henry's law

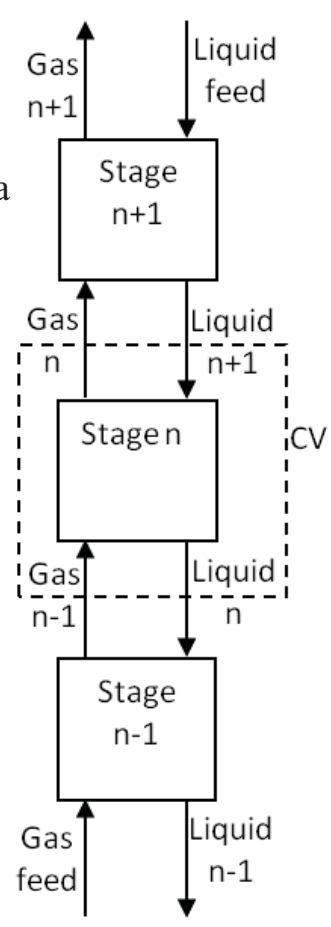

- Adiabatic system

Figure 2: Discrete, stagewise model with countercurrent flow. 


\subsection{Governing Equations}

Component mass and energy balance equations for the rate based-model are written separately for the gas and liquid phases. The mass balance equations ${ }^{5,7,8}$ are

gas phase:

$$
\frac{d C_{i, n}^{G}}{d t}=\frac{G}{V}\left(C_{i, n-1}^{G}-C_{i, n}^{G}\right)-N_{i}+r_{i}^{G} \varphi^{G}
$$

liquid phase:

$$
\frac{d c_{i, n}^{L}}{d t}=\frac{L}{V}\left(C_{i, n+1}^{L}-C_{i, n}^{L}\right)+N_{i}+r_{i}^{L} \varphi^{L}
$$

Where:

$$
\begin{array}{ll}
C_{i, n}^{G} ; C_{i, n}^{L} & =\text { Concentration of gas }(\mathrm{G}) \text { and liquid }(\mathrm{L}) \text { phase component } \mathrm{i} \text { at stage } \mathrm{n} ; \mathrm{mol} / \mathrm{m}^{3} \\
\mathrm{G}, \mathrm{L} & =\text { Gas and liquid stream flow rate, respectively; } \mathrm{m}^{3} / \mathrm{s} \\
\mathrm{V} & =\text { Volume of a single stage; } \mathrm{m}^{3} \\
\mathrm{~N}_{\mathrm{i}} & =\text { Mass flux; } \mathrm{mol} /\left(\mathrm{m}^{3} \mathrm{~s}\right) \\
\mathrm{r}_{\mathrm{i}}^{\mathrm{G}} ; \mathrm{r}_{\mathrm{i}}^{\mathrm{L}} & =\text { Overall rate of reaction of component } \mathrm{i} \text { in gas and liquid phase; } \mathrm{mol} /\left(\mathrm{m}^{3} \mathrm{~s}\right) \\
\varphi^{\mathrm{G}} ; \varphi^{\mathrm{L}} & =\text { Gas and liquid phase holdup; } \mathrm{m}^{3} / \mathrm{m}^{3} \\
\mathrm{t} & =\text { time, } \mathrm{s}
\end{array}
$$

To be able to reflect the change in temperature in both phases from stage to stage, the energy balances ${ }^{5,7,8}$ are

gas phase: $\quad \frac{d T_{n}^{G}}{d t}=\frac{G}{V}\left(T_{n-1}^{G}-T_{n}^{G}\right)-\frac{1}{\sum\left(c_{i}^{G} c_{p, i}\right)}\left(q-Q^{G}\right)$

liquid phase: $\quad \frac{d T_{n}^{L}}{d t}=\frac{L}{V}\left(T_{n+1}^{L}-T_{n}^{L}\right)+\frac{1}{\sum\left(c_{i}^{L} c_{p, i}\right)}\left(q+Q^{L}\right)$

Where:

$$
\begin{aligned}
& T_{n}^{G} ; T_{n}^{L}=\text { temperature of gas and liquid phase at stage } \mathrm{n} ; \mathrm{K} \\
& \mathrm{C}_{\mathrm{p}, \mathrm{i}}=\text { heat capacity of component } \mathrm{i} ; \mathrm{J} /\left(\mathrm{mol}^{*} \mathrm{~K}\right) \\
& \mathrm{q} \quad=\text { heat flux due to heat transfer; } \mathrm{J} /\left(\mathrm{m}^{3} \mathrm{~s}\right) \\
& \mathrm{Q}^{\mathrm{G}} ; \mathrm{Q}^{\mathrm{L}}
\end{aligned}
$$

\subsection{Initial Conditions}

Initial conditions $(\mathrm{t}=0)$ for the absorption process described by the governing equations are given by:

$$
\begin{gathered}
C_{i, n}^{G}=0 \\
C_{i, n}^{L}=0 \\
T=T_{o}
\end{gathered}
$$

where:

$$
\mathrm{T}_{\mathrm{o}}=\text { initial column temperature, } \mathrm{K}
$$




\subsection{Parameter Evaluation}

The mass flux, or rate of mass transfer, is described by the following equation:

$$
N_{i}=K_{g} a^{I}\left(C_{i, n}^{G}-C_{i, n}^{G *}\right)
$$

Where the gas phase concentration at equilibrium, $C_{i, n}^{G *}$, is described by Henry's Law:

$$
C_{i, n}^{L}=H_{i} R T_{n}^{G} C_{i, n}^{G *}
$$

And $\mathrm{K}_{\mathrm{g}}=$ Overall mass transfer coefficient for component $\mathrm{i} ; \mathrm{m} / \mathrm{s}$

$$
\begin{aligned}
& \mathrm{a}^{\mathrm{I}}=\text { specific interfacial area; } \mathrm{m}^{2} / \mathrm{m}^{3} \\
& \mathrm{H}_{\mathrm{i}}=\text { Henry's constant of component } \mathrm{i} ; \mathrm{mol} /\left(\mathrm{m}^{3} \mathrm{~Pa}\right) \\
& \mathrm{R}=\text { gas constant } ; 8.314\left(\mathrm{~m}^{3} \mathrm{~Pa}\right) /\left(\mathrm{mol}^{*} \mathrm{~K}\right)
\end{aligned}
$$

Henry's law is applied to relate the concentration of the absorptive species in the bulk liquid phase to the bulk vapor phase concentration. By applying Henry's law as well as an overall mass transfer coefficient, the interface concentration can be eliminated and a relationship between the bulk vapor and liquid applied. ${ }^{9,10}$

The heat flux due to heat transfer and heat flux due to chemical reactions ${ }^{11}$ in gas and liquid phases are described, respectively, by:

$$
\begin{gathered}
q=h a^{I}\left(T_{n}^{G}-T_{n}^{L}\right) \\
Q^{G}=\sum_{j=1}^{N o R x n}\left[\left(-\Delta H_{r x n, j}\right) r_{j}^{G}\right] \\
Q^{L}=\sum_{j=1}^{N o R x n}\left[\left(-\Delta H_{r x n, j}\right) r_{j}^{L}\right]
\end{gathered}
$$

Where:

$$
\begin{aligned}
& \mathrm{h}=\text { heat transfer coefficient; } \mathrm{J} /\left(\mathrm{m}^{2} \mathrm{~s} * \mathrm{~K}\right) \\
& \Delta H_{r x n, j}=\text { heat of reaction of reaction } \mathrm{j} ; \mathrm{J} / \mathrm{mol}
\end{aligned}
$$




\section{5 $\quad \mathrm{NO}_{\mathrm{x}}$ Absorption Kinetics}

Absorption of nitrous gases is highly complex due to the interactions of several components and chemical reactions in both the liquid and gas phases. ${ }^{5}$ The model was developed around this process in order to obtain an initial model from which this unit operation would be extended to be adaptable for the absorption of other off-gas constituents. Equations for rates of reactions, rate constants, equilibrium constants, and heat liberated are specifically for the $\mathrm{NO}_{\mathrm{x}}$ process.

$\mathrm{NO}_{\mathrm{x}}$ is a mixture of various nitrogen oxides and, in the presence of water vapor, nitrous oxyacids also exist. ${ }^{12}$ Chemical reactions are important in $\mathrm{NO}_{\mathrm{x}}$ absorption because they enhance the absorption of components that are otherwise insoluble in water through their chemical transformation to more soluble components. For example, $\mathrm{NO}$, insoluble in water, is oxidized to $\mathrm{NO}_{2}$, which is more soluble. ${ }^{5}$ The absorption of $\mathrm{NO}_{\mathrm{x}}$ in water produces nitric acid through the complex reaction mechanism described below.

Gas phase reactions:

$$
\begin{gathered}
2 \mathrm{NO}+\mathrm{O}_{2} \rightarrow 2 \mathrm{NO}_{2} \\
2 \mathrm{NO}_{2} \leftrightarrow \mathrm{N}_{2} \mathrm{O}_{4} \\
\mathrm{NO}+\mathrm{NO}_{2} \leftrightarrow \mathrm{N}_{2} \mathrm{O}_{3} \\
\mathrm{NO}+\mathrm{NO}_{2}+\mathrm{H}_{2} \mathrm{O} \leftrightarrow 2 \mathrm{HNO}_{2} \\
3 \mathrm{NO}_{2}+\mathrm{H}_{2} \mathrm{O} \leftrightarrow 2 \mathrm{HNO}_{3}+\mathrm{NO}
\end{gathered}
$$

Liquid phase reactions:

$$
\begin{gathered}
2 \mathrm{NO}_{2}+\mathrm{H}_{2} \mathrm{O} \rightarrow \mathrm{HNO}_{2}+\mathrm{HNO}_{3} \\
\mathrm{~N}_{2} \mathrm{O}_{3}+\mathrm{H}_{2} \mathrm{O} \rightarrow 2 \mathrm{HNO}_{2} \\
\mathrm{~N}_{2} \mathrm{O}_{4}+\mathrm{H}_{2} \mathrm{O} \rightarrow \mathrm{HNO}_{2}+\mathrm{HNO}_{3} \\
3 \mathrm{HNO}_{2} \rightarrow \mathrm{HNO}_{3}+\mathrm{H}_{2} \mathrm{O}+2 \mathrm{NO}
\end{gathered}
$$

The oxidation of nitrous oxide is irreversible, the remaining four gas phase reactions are reversible and instantaneous, and the liquid phase reactions are reversible. The reaction rates for forward and backward reactions of instantaneous reactions equal zero. The rate expressions for R1-R9, the reaction rate constants for R1 and R6-R97, and the equilibrium constants for R2-R $5^{12}$ used to describe the above set of reactions in the model are given in Table 1. The third column labeled 'With Respect To' states which component in the reaction the rate expression is based on. Stoichiometry is used to determine the rates for the other components in the reaction. The rate expression used for R9 is given by Loutet, et al. ${ }^{8}$ 
Table 1: Reaction Properties for $\mathrm{NO}_{\mathrm{x}}$ Absorption

\begin{tabular}{|c|c|c|c|c|}
\hline Reaction & Rate Expression & $\begin{array}{l}\text { With } \\
\text { Respect } \\
\text { To }\end{array}$ & $\begin{array}{l}\text { Parameter } \\
\text { (units) }\end{array}$ & Value \\
\hline R1 & $r_{1}=-k_{1}[N O]^{2}\left[O_{2}\right]$ & NO & $\begin{array}{c}\mathrm{k}_{1} \\
\left(m^{6} \mathrm{~mol}^{-2} s^{-1}\right)\end{array}$ & $\left(10^{\frac{652.1}{T}-0.7356}\right)\left(\frac{R T}{101325}\right)^{2}$ \\
\hline R2 & $r_{2}=-k_{2}\left(\left[\mathrm{NO}_{2}\right]^{2}-\frac{\left[\mathrm{N}_{2} \mathrm{O}_{4}\right]}{K_{2}}\right)$ & $\mathrm{NO}_{2}$ & $\begin{array}{c}\mathrm{K}_{2} \\
\left(m^{3} \mathrm{~mol}^{-1}\right)\end{array}$ & $\left(10^{\frac{2993}{T}-9.226}\right)\left(\frac{R T}{101325}\right)$ \\
\hline R3 & $r_{3}=-k_{3}\left([N O]\left[\mathrm{NO}_{2}\right]-\frac{\left[\mathrm{N}_{2} \mathrm{O}_{3}\right]}{K_{3}}\right)$ & NO & $\begin{array}{c}\mathrm{K}_{3} \\
\left(m^{3} m o l^{-1}\right)\end{array}$ & $\left(10^{\frac{2072}{T}-7.234}\right)\left(\frac{R T}{101325}\right)$ \\
\hline R4 & $r_{4}=-k_{4}\left([\mathrm{NO}]\left[\mathrm{NO}_{2}\right]\left[\mathrm{H}_{2} \mathrm{O}\right]-\frac{\left[\mathrm{HNO}_{2}\right]^{2}}{K_{4}}\right)$ & NO & $\begin{array}{c}\mathrm{K}_{4} \\
\left(m^{3} m o l^{-1}\right)\end{array}$ & $\left(10^{\frac{2051.17}{T}-6.733}\right)\left(\frac{R T}{101325}\right)$ \\
\hline R5 & $r_{5}=-k_{5}\left(\left[\mathrm{NO}_{2}\right]^{3}\left[\mathrm{H}_{2} \mathrm{O}\right]-\frac{\left[\mathrm{HNO}_{3}\right]^{2}[\mathrm{NO}]}{K_{5}}\right)$ & $\mathrm{NO}_{2}$ & $\begin{array}{c}\mathrm{K}_{5} \\
\left(m^{3} m o l^{-1}\right)\end{array}$ & $\left(10^{\frac{2003.8}{\tau}-8.757}\right)\left(\frac{R T}{101325}\right)$ \\
\hline R6 & $r_{6}=-k_{6}\left[\mathrm{NO}_{2}\right]^{2}$ & $\mathrm{NO}_{2}$ & $\begin{array}{c}\mathrm{k}_{6} \\
\left(m^{3} m o l^{-1} s^{-1}\right)\end{array}$ & $10^{4.67209}$ \\
\hline R7 & $r_{7}=-k_{7}\left[N_{2} O_{3}\right]$ & $\mathrm{N}_{2} \mathrm{O}_{3}$ & $\begin{array}{c}\mathrm{k}_{7} \\
\left(s^{-1}\right)\end{array}$ & $10^{4.23044}$ \\
\hline $\mathrm{R} 8$ & $r_{8}=-k_{8}\left[N_{2} O_{4}\right]$ & $\mathrm{N}_{2} \mathrm{O}_{4}$ & $\begin{array}{c}\mathrm{k}_{8} \\
\left(s^{-1}\right)\end{array}$ & $\left(10^{-\frac{4139}{\tau}+16.3415}\right)$ \\
\hline R9 & $r_{9}=-k_{9} \frac{\left[\mathrm{HNO}_{2}\right]^{4}}{\left[\mathrm{NO}_{2}\right]^{2}(\mathrm{RT})^{2}}$ & $\mathrm{HNO}_{2}$ & $\begin{array}{c}\mathrm{k}_{9} \\
\left(a t m^{2} m^{9} \mathrm{~mol}^{-3} s^{-1}\right)\end{array}$ & $\left(10^{-\frac{6200}{\tau}+20.1979}\right)$ \\
\hline
\end{tabular}

The governing equations describing the adsorption process for off-gas separation along with the initial conditions and supporting equations were solved in the gPROMS modeling software. This was found to give a converged solution in a few seconds and in which balance errors were less than $1 \%$.

\section{RESULTS AND DISCUSSION}

\subsection{Current Absorption Model}

The off-gas separation system modeled by the above equations is a dynamic, rate-based, discrete, and reactive absorption system. It is a two phase multiple component system with countercurrent flow that accounts for absorption by mass transfer and chemical reaction and is solved stagewise. The model describes the component concentration, phase composition, and temperature in each phase at each stage. The model allows for a wide range of user inputs and can easily be scaled up to be used for systems larger than a bench scale model. The number of stages, number of reactions in both the liquid and gas phase, and number of components for each stage can be adjusted as needed. 
The inputs for the model, which are user-specified, include inlet concentrations, flow rates of the gas and liquid inlet streams, inlet temperature, inlet pressure, column diameter, column height, number of stages, components, number of reactions, reaction properties, and properties of liquid and gas components.

Component concentrations of both phases, composition of each phase, and temperatures for each stage as a function of time are simulation outputs. Figure 3 shows an example of the concentration output.

The number of stages controls the discretization of the entire column because the column height is divided into the number of specified stages that are of equal height. The more stages the system contains, the more times the column height is divided. The simulation accuracy and set of equations grows with the number of stages also. This could impact the simulation time causing it to become longer, however, the gPROMS software is very robust and can solve an extensive number of equations simultaneously in much less than a minute. If this becomes an issue, the user will need to find the optimum amount of stages that

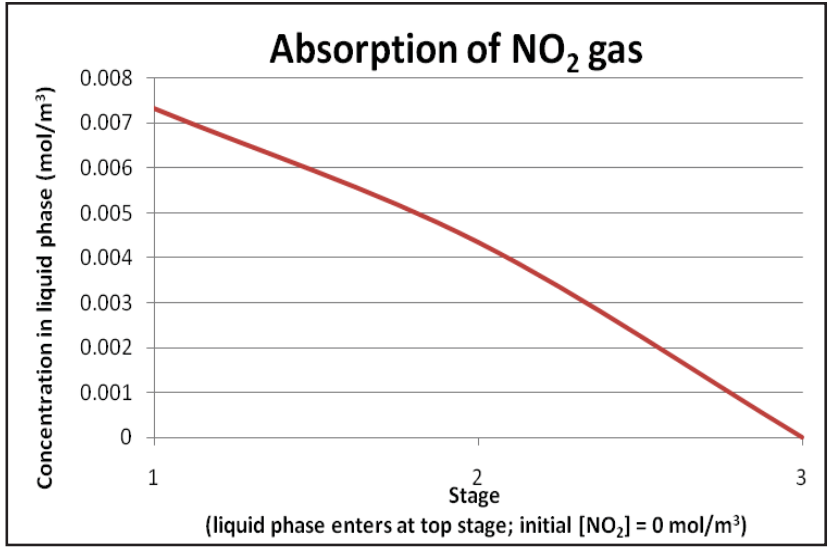

Figure 3: Example of model output. provides the needed accuracy within a reasonable solution time.

The governing equations have been written in a general form so the model would not need to undergo extensive work to be modified for another absorption system, i.e. $\mathrm{CO}_{2}$. This will allow for the specific off-gas system to be changed. However, the current model is set up in such a way that the kinetic parameters are written specifically for a $\mathrm{NO}_{\mathrm{x}}$ absorption system. The kinetics can also be modified for another system, i.e. $\mathrm{CO}_{2}$, by the user but may require more time than simply inputting system specific constants.

\subsection{Future Absorption Model Work}

As previously discussed, the current model is being developed based on the absorption of $\mathrm{NO}_{\mathrm{x}}$. $\mathrm{The}^{\mathrm{NO}} \mathrm{x}$ specific model may be improved by not assuming the four latter gas phase reactions are instantaneous. This would entail determining rate constants for the forward reactions, which could be accomplished by performing additional literature searches, experimentation, or by using software or a model that has been developed for determining reaction kinetics.

Future work for the development of the generic absorption model includes the development of a userfriendly interface, the addition of a pressure drop equation, the inclusion of an additional stream for nonabsorptive species, and the addition of an equation for the gas phase flow rate instead of assuming it to be constant. A user-friendly interface will be developed in Excel and will allow the user to input systemspecific parameters into an Excel workbook that is interfaced with the gPROMS model. The output will be sent to the same Excel workbook. This prevents the user from having to learn the gPROMS software in order to simulate an absorption system of interest. In addition, the user-friendly interface will make the model even more generic and easier to modify for a completely different system. Anything that is system specific can most likely be included in the interface instead of the model codes.

An additional stream for species that do not interact within in a specific absorption system will act like a stream of inert species and pass them directly on to the next unit operation in which they may no longer act as an inert species. This will avoid any complications with losing or gaining species from one unit operation to the next within the integration of multiple unit operations. The components of the bypass stream will also be available for the calculation of the composition of the off-gas stream at any time within the treatment system. 
In addition to the discrete (tray column) system being modeled in this report, the development of a model to describe a continuous (packed column) absorption system will improve the generic absorption model. A continuous system would include partial differential equations (PDEs) for the concentration and temperature profiles instead of ordinary differential equations (ODEs) as seen in the discrete system. The use of PDEs would generate outlet concentrations and temperatures as a function of time and distance from the inlets, whereas the discrete system output is only a function of time.

The model fidelity may also be increased by evaluating the concentrations at the interface and/or in the film layers on either side of the interface between the bulk layers of the two phases. This would entail utilizing a more complete two-film model to describe the system.

Model validation is a necessary step in developing an accurate model. In order to validate the absorption model, experimental data are required for the system being modeled. These data probably already exist and may be available in literature. Therefore, additional literature searches or delving more deeply into the literature already found during model development may be all that is required to validate the model. Another validation method would be to perform the experiments at the lab or bench scale. The latter method would require time and funding.

The development of a $\mathrm{CO}_{2}$ specific absorption system is also planned. The absorption models will be integrated with other off-gas treatment unit operations, i.e. adsorption, and a partial flow sheet for the offgas treatment system will be generated. This will allow for the evaluation of the models' flow sheeting capability. The off-gas treatment system will eventually be integrated with the plant level nuclear fuel reprocessing model. The absorption model(s) will be made available for evaluation by customers, specifically the Sigma Off-Gas Team, along with the adsorption model(s). The feedback from this evaluation period will aid in further development of the models.

\section{CONCLUSIONS}

In conclusion, an initial model has been developed to be used as the framework for the reference case unit operation for the removal of $\mathrm{NO}_{\mathrm{x}}$ from off-gas generated during the reprocessing of nuclear fuel. This dynamic model has been created for absorption in a tray column system with countercurrent flow of the gas and liquid phases. It is a rate-based model that can be used for multiple components and reactions and is solved stagewise. Future plans include modifying the model for countercurrent $\mathrm{CO} 2$ absorption, development of a user-friendly interface, and a myriad other modifications and improvements that can and will be done to improve the model. The current model will be expanded and built upon to simulate the absorption process with more accuracy. 


\section{REFERENCES}

1. Haefner, Daryl, et.al. "System Design Description and Requirements for Modeling the Off-Gas Systems for Fuel Recycling Facilities,” INL-2010, Idaho National Laboratory, 2010.

2. Rutledge, Veronica J., "Adsorption Model for Off-Gas Separation," INL-2011, Idaho National Laboratory, 2011.

3. Schneider, Ralf, et.al. "Review: Model Optimization for the Dynamic Simulation of Reactive Absorption Processes," Chem. Eng. Technol., 2001, 24, 979.

4. Tranter, Troy. "Simulation Platform for Modeling Nuclear Fuel Separations Processes," INL-2010, Idaho National Laboratory, 2010.

5. Kenig, Eugeny, et.al. "Modeling Reactive Absorption," Chem. Eng. Progress, 2009, 65.

6. Lawal, A., et.al. "Dynamic modeling of $\mathrm{CO}_{2}$ absorption for post combustion capture in coal-fired power plants," Fuel, 2009, 88, 2455.

7. Hupen, Bernhard, et.al. "Rigorous modeling of $\mathrm{NO}_{\mathrm{x}}$ absorption in tray and packed columns," Chem. Eng. Sci., 2005, 60, 6462.

8. Loutet, Kyle G., et.al. "Experimental Measurements and Mass Transfer/Reaction Modeling for an Industrial $\mathrm{NO}_{\mathrm{x}}$ Absorption Process," Ind. Eng. Chem. Res., 2011, 50, 2192.

9. Harun, Noorlisa, et.al. "Dynamic Simulation of MEA Absorption Processes for $\mathrm{CO}_{2}$ Capture from Fossil Fuel Power Plant," Energy Procedia, 2011, 4, 1478.

10. Greer, Timothy, et.al. "A dynamic model for the de-sorption of carbon dioxide from Monoethanolamine solution," Selected Works, 2008, Available at http://works.bepress/joao_gomes/21.

11. Emig, G., et.al. "Absorption with Simultaneous Complex Rections in both phases, Demonstrated by modeling and calculation of a countercurrent flow column for the production of nitric acid," Comp. \& Chem. Eng., 1979, 3, 143.

12. Suchak, N. J., et.al. "Modeling and Simulation of $\mathrm{NO}_{\mathrm{x}}$ Absorption in Pilot-Scale Packed Columns," AIChE Journal, 1991, 37, 323. 